\title{
CUTINASES FÚNGICAS: PROPRIEDADES E APLICAÇÕES INDUSTRIAIS
}

\author{
Tatiana Fontes Pio*, Laira Priscila Fraga e Gabriela Alves Macedo \\ Departamento de Ciência de Alimentos, Faculdade de Engenharia de Alimentos, Universidade Estadual de Campinas, 13083-862 \\ Campinas - SP, Brasil
}

Eliana Setsuko Kamimura

Departamento de Engenharia de Alimentos, Faculdade de Zootecnia e Engenharia de Alimentos, Universidade Estadual de São Paulo, 13635-900 Pirassununga - SP, Brasil

Recebido em 18/12/07; aceito em 20/6/08; publicado na web em 10/11/08

\begin{abstract}
FUNGAL CUTINASES: PROPERTIES AND INDUSTRIAL APPLICATIONS - REVIEW.Cutinases (EC 3.1.1.74) are also known as cutin hidrolases. These enzymes share catalytic properties of lipases and esterases, presenting a unique feature of being active regardless the presence of an oil-water interface, making them interesting as biocatalysts in several industrial processes involving hydrolysis, esterification and trans-esterification reactions. They are also active in different reaction media, allowing their applications in different areas such as food industry, cosmetics, fine chemicals, pesticide and insecticide degradation, treatment and laundry of fiber textiles and polymer chemistry. The present review describes the characteristics, potential applications and new perspectives for these enzymes.
\end{abstract}

Keywords: cutinase; industrial applications; biochemical characteristics.

\section{INTRODUÇÃO}

Cutinases são enzimas que catalisam a hidrólise de um biopoliéster insolúvel, a cutina, componente estrutural da cutícula das plantas. ${ }^{1}$ Este poliéster é composto do seguintes ácidos graxos: -hidróxi ácidos graxos, ácido diidroxidróxi palmítico, e ácidos 18-hidróxi-9,10,-epóxi $\mathrm{C}_{18}$ saturados e $\Delta 12$ insaturados, e ácidos 9,10,18-triidróxi $\mathrm{C}_{18}$ saturados e $\Delta 12$ monoinsaturados. A composição da cutina é dependente da espécie, porém, em geral, em plantas de crescimento rápido predominam os ácidos de 16 carbonos, particularmente diidroxipalmitato, enquanto em plantas de crescimento lento uma mistura de ácidos de 16 e 18 carbonos é encontrada. A cutinase libera hidroliticamente todos os tipos de monômeros a partir do polímero. ${ }^{2}$

Além da hidrólise, assim como as lipases, as cutinases também são capazes de catalisar reações reversas, como esterificação, transesterificação (interesterificação, alcoólise e acidólise) e aminólise, sendo que a atividade de água do meio reacional é um dos fatores determinantes para cada classe de reação.,

Segundo Brenda ${ }^{5}$ a cutinase é classificada como EC 3.1.1.3 com nome recomendado de triacilglicerol lipase, e nome sistemático de triacilglicerolacil-hidrolase. Também é classificada, pela mesma fonte, como 3.1.1.74 com nome recomendado de cutinase e nome sistemático de cutina hidrolase, ou seja, uma esterase que hidrolisa a cutina, podendo agir e ser classificada também como lipase.

As cutinases apresentam diversas características interessantes para aplicações em uma ampla gama de produtos, variando de detergentes a alimentos. ${ }^{6}$ Conseqüentemente, tem sido desenvolvida intensa pesquisa abordando suas estruturas, funções, purificação e aplicações, visando o desenvolvimento de novos processos empregando este grupo de enzimas. ${ }^{1}$

O presente artigo descreve as características e potenciais aplicações das cutinases fúngicas em processos industriais.

\footnotetext{
*e-mail: tatipi@fea.unicamp.br
}

\section{Características das cutinases}

Cutinases são dos menores membros da família serina hidrolase, que apresenta a tríade catalítica clássica composta por serina, histidina e um grupo carboxil. A sub-família das cutinases consiste em cerca de 20 membros, baseada em sequiência de aminoácidos similares. Suas estruturas e dinâmica molecular são conhecidas em detalhes após extensivos estudos de cristalografia por raios X e RMN. Em todas serina hidrolases, o sítio ativo está invariavelmente localizado na extremidade $\mathrm{C}$-terminal de uma das cadeias $\beta .^{7}$

Trata-se de uma molécula compacta que consiste em 197 resíduos, é uma $\alpha / \beta$ proteína com núcleo hidrofóbico que compreende uma folha $\beta$ central rodeada por $5 \alpha$ hélices ligeiramente torcidas, contendo um único resíduo triptofano $\left(\operatorname{Trp}_{69}\right)$ que está localizado na vizinhança de uma ponte dissulfeto $\left(\mathrm{Cys}_{31}-\mathrm{Cys}_{109}\right){ }^{8}$

Segundo Borreguero et al. ${ }^{9}$ o sítio catalítico da cutinase não é protegido por alça (tampa) helicoidal anfipática, a qual está caracteristicamente presente nas lipases. O sítio oxiânion, que nas lipases é formado sobre a ligação com o substrato, é pré-formado nas cutinases. Estes dois fatores poderiam ser responsáveis pela ausência da ativação interfacial detectada no comportamento catalítico da cutinase.

Melo et al..$^{10}$ descrevem, em algumas cutinases, a presença de um sítio de conformação que abre e fecha, o que indicaria ser a enzima preferencialmente uma lipase que uma esterase. Este movimento de "mini-tampa" da cutinase cobrindo seu sítio ativo poderia ser responsável por sua adaptação a diferentes solventes.

A atividade catalítica da cutinase depende de alguns parâmetros, como o $\mathrm{pH}$. Petersen et al. ${ }^{11}$ descrevem que a estrutura tridimensional da cutinase permanece estável em uma faixa de $\mathrm{pH}$ entre 4,0 e 9,0. Contudo, a atividade ótima foi observada em uma faixa de $\mathrm{pH}$ ente 4,0 e 5,0; e também em torno de 8,5. Este comportamento foi atribuído ao estado de ionização de His-188. Este resíduo precisa ser desprotonado para estabilizar o sítio catalítico. As cutinases fúngicas apresentam estabilidade em $\mathrm{pH}$ ácido e básico, contrastando com a cutinase de pólen, a qual apresenta estabilidade apenas em $\mathrm{pH}$ neutro, com pH ótimo em $6,8 .{ }^{12}$ 
Diversas estratégias tem sido empregadas com o objetivo de aumentar a estabilidade térmica e operacional das cutinases em diferentes meios de reação. ${ }^{13-17} \mathrm{O}$ uso de micelas reversas, principalmente AOT, é a estratégia mais freqüentemente empregada na literatura, devido ao maior ganho de atividade obtido. ${ }^{16}$ Micelas reversas são sistemas compostos por moléculas anfifílicas que se auto-organizam de forma que seus grupamentos polares se orientam para a face interna e a parte apolar se encontra na face externa. Sua estrutura apresenta características semelhantes às membranas biológicas. Este aspecto as torna um conveniente meio para o estudo das interações biológicas de peptídeos bioativos. ${ }^{16}$

O emprego de álcoois, principalmente o hexanol, apresenta influência positiva na retenção de atividade da cutinase em micelas reversas, embora o mecanismo exato de tal efeito ainda não esteja totalmente elucidado. ${ }^{18}$

Gonçalves et al. ${ }^{19}$ demonstraram que a cutinase possui alta estabilidade quando imobilizada em dextrana e suportes derivados de sílica.

\section{APLICAÇÕES DA CUTINASE}

As cutinases são enzimas versáteis, demonstrando várias propriedades úteis para a aplicação em produtos e processos industriais (Tabela 1). A atividade estereolítica da cutinase tem sido largamente explorada. Fazendo uso de sua atividade cutinolítica in vivo, uma preparação enzimática contendo cutinase foi desenvolvida para aumentar o efeito farmacológico de defensivos agrícolas. ${ }^{10}$ Uma aplicação particularmente importante, na qual estas enzimas possuem grande potencial, é o manejo de resíduos gerados pelo processamento de frutas e vegetais. Cascas de tomate, maçã e frutas cítricas podem ser utilizadas como matérias-primas para a obtenção do ácido ricinoléico por meio da hidrólise por cutinases. Este ácido é bastante empregado em indústrias farmacêuticas, tendo como fonte principal de obtenção o óleo de mamona. ${ }^{13}$

Cutinases apresentam, in vitro, atividade hidrolítica sobre uma grande variedade de ésteres, desde ésteres sintéticos solúveis, como $p$-nitrofenil ésteres, a triglicerídeos insolúveis de cadeia longa, como trioleína e tricaprilina, bem como triacilgliceróis emulsificados. ${ }^{7}$

A cutinase pode também ser utilizada na síntese de triglicerídeos estruturados, polímeros, surfactantes, ingredientes para produtos de higiene pessoal, química farmacêutica e agroquímicos contendo um ou mais centros quirais. ${ }^{20}$

A enzima tem sido aplicada como uma enzima lipolítica na composição de detergentes de roupas e louças. ${ }^{21}$ Algumas vantagens foram obtidas quando a cutinase foi comparada com uma lipase comercial (Lipolase ${ }^{\mathrm{TM}}$ ) para remoção de triacilgliceróis em um processo de lavagem simples, pois a cutinase é capaz de hidrolisar gorduras na ausência do cálcio. ${ }^{21}$
Atualmente está bem estabelecido que muitas enzimas, quando em meios não aquosos, são capazes de catalisar reações impossíveis de ocorrer em meio aquoso, tornando-se inclusive mais estáveis e com especificidade modificada. ${ }^{22}$ Neste contexto, o emprego de enzimas em presença de fluidos supercríticos tem sido considerada uma interessante estratégia para a obtenção de processos produtivos que aliem alto rendimento e baixo impacto ambiental. ${ }^{23}$

\section{Indústria de laticínios e óleos}

Trans-esterificação de gorduras e óleos ou esterificação estereosseletiva de álcoois pode ser obtida em baixa atividade de água utilizando cutinase..$^{20}$

As enzimas hidrolíticas têm sido muito empregadas na tecnologia de modificação de óleos e gorduras. ${ }^{23-26}$ Esta tendência pode ser atribuída principalmente ao fato desses materiais serem obtidos de fontes naturais e empregados como importantes matérias-primas para as indústrias química, farmacêutica e alimentícia. Existem casos em que se torna necessário modificar as características desses materiais, para adequá-los a uma determinada aplicação. Portanto, o setor industrial de óleos e gorduras tem desenvolvido diversos processos para manipular a composição das misturas de triglicerídeos. ${ }^{27-29}$ Apesar das lipases terem sido, até o momento, as enzimas mais empregadas neste contexto, as cutinases possuem também considerável potencial, devido a suas características particulares.

A hidrólise parcial da gordura do leite é uma transformação tipicamente dependente de enzimas, intrínseca à produção de diversos derivados lácteos. Tal processo pode ser realizado por enzimas pertencentes à microflora nativa, como ocorre na produção de queijo a partir de leite cru, ou pela adição deliberada de enzimas exógenas. Dependendo da extensão e especificidade de tal hidrólise a gordura láctea, enzimaticamente modificada irá exibir diferentes aromas e sabores: desde tons livres de acidez até sabor de creme de queijo ou manteiga. Regado et al. ${ }^{30}$ avaliaram o uso de 10 lipases microbianas e da cutinase de Fusarium solani pisi na lipólise parcial de gordura láctea. Os ácidos graxos liberados no meio de reação foram analisados por HPLC. Os sistemas testados apresentaram nível de modificação enzimática equivalente aos sistemas comerciais já empregados. Porém dentre todas as enzimas testadas, a cutinase apresentou a maior atividade sobre os ácidos graxos de cadeia curta.

\section{Compostos de aroma}

Ésteres produzidos a partir de ácidos graxos de cadeia curta são importantes componentes de aromas e fragrâncias, muito utilizados em diversas áreas, como nas indústrias de bebidas, alimentos,

Tabela 1. Aplicações biocatalíticas descritas para cutinases

\begin{tabular}{|c|c|c|c|c|}
\hline $\begin{array}{l}\text { Número da } \\
\text { Publicação }\end{array}$ & $\begin{array}{c}\text { Data da } \\
\text { Publicação }\end{array}$ & Inventor & Nome & Ref. \\
\hline WO8809367 & 01-12-1988 & Kolattukudy et al. & Composições e métodos do uso de cutinase em limpeza & 69 \\
\hline JP3088897 & 15-04-1991 & Eruuseido et al. & $\begin{array}{l}\text { Método de utilização de lipases e surfactantes de cutinases úteis } \\
\text { para lavagem }\end{array}$ & 70 \\
\hline NZ337239 & 28-09-2001 & Rainhard e Henrik & Método de degradação enzimática de polímeros biodegradáveis. & 71 \\
\hline EP1694903 & $30-08-2006$ & Cavaco-Paulo et al. & Método de modificação de fibras de poliacrilonitrila e de poliamida. & 72 \\
\hline JP2005058228 & 10-03-2005 & Yoshinobu et al. & Método de produção de ésteres na ausência de solventes orgânicos. & 73 \\
\hline CA 2480912 & $23-10-2003$ & Salmon et al. & $\begin{array}{l}\text { Método para melhorar a resistência a abrasão e força de tensão a materiais } \\
\text { celulósicos como o algodão. }\end{array}$ & 74 \\
\hline CA 1262860 & 14-11-1989 & Yuichi, et al. & Método para aumentar o efeito de biocidas em agricultura. & 75 \\
\hline CA 2060510 & 10-01-1991 & Ayrookaran, et al. & Método para aumentar a permeabilidade da superfície de frutas e vegetais. & 76 \\
\hline CA 2465250 & $15-05-2003$ & Shi, et al. & Método para remover a tintura adicional de materiais têxteis tingidos. & 77 \\
\hline
\end{tabular}


cosméticos e farmacêutica. Embora estes ésteres aromáticos sejam atualmente produzidos por síntese química, existe uma crescente preferência por aromas naturais. ${ }^{31}$

Os ésteres obtidos por síntese química não podem ser considerados aromas naturais sendo, portanto, menos valorizados no mercado que os demais. Contudo, aqueles sintetizados biotecnologicamente podem ser considerados naturais. Os ésteres de ácidos graxos podem ser produzidos com razoável grau de pureza através de reações catalisadas por enzimas. ${ }^{32}$ Avanços recentes em biocatálise empregando meios não convencionais tornaram possível a utilização de enzimas hidrolíticas para catalisar a síntese de compostos aromáticos. ${ }^{33,34}$

Carvalho et al. ${ }^{13}$ estudaram os parâmetros da reação de transesterificação de butil acetato com hexanol, utilizando cutinase recombinante de Fusarium solani pisi em micelas reversas de bis (2-etil1-hexil) sulfosuccinato de sódio (AOT)/ isooctano para a obtenção de hexil acetato, um éster de cadeia curta com aroma de fruta. Este tipo de reação é potencialmente importante para a síntese de ésteres aromáticos. Neste estudo, a enzima apresentou alta atividade em temperaturas entre 40 e $50{ }^{\circ} \mathrm{C}$. A relação molar água: surfactante influenciou muito a atividade da enzima, apresentando faixa ótima entre 5 e 8 . A presença do hexanol e o reduzido conteúdo de água promovem a estabilização da estrutura da enzima no interior das micelas aumentando sua termoestabilidade. ${ }^{14,15}$

O emprego de enzimas encapsuladas em micelas reversas fornece uma área de interface muito grande, tornando possível a solubilização de substratos hidrofílicos e hidrofóbicos e freqüentemente aumentando a atividade catalítica. A separação dos produtos de reação bem como a recuperação da enzima são facilitados e constituem uma importante área de pesquisa relacionada ao uso de micelas. ${ }^{35}$

Barros et al. $^{36}$ estudaram os parâmetros de reação referentes à esterificação do etanol com ácidos graxos de cadeia curta $\left(\mathrm{C}_{2} \mathrm{a}_{6}\right)$ em meio orgânico utilizando cutinase. Houve aumento de $35 \%$ na conversão molar, quando a concentração da enzima foi alterada de 1,4 para $2,1 \%$.

\section{Compostos fenólicos}

A família dos ácidos fenólicos é composta pelos derivados dos ácidos cinâmico $\left(\mathrm{C}_{6}-\mathrm{C}_{3}\right)$ e benzóico $\left(\mathrm{C}_{6}-\mathrm{C}_{1}\right)$, Figuras 1 e 2 , caracterizando-se por conter um anel benzênico em sua estrutura com um ou mais hidroxilas, ou um grupo metoxila, e um grupo carboxílico. São antioxidantes hidrofílicos naturais, com presença ubíqua em frutas, vegetais e ervas aromáticas. Apresentam particular interesse devido a propriedades tais como antioxidantes, quelantes, sequiestradores de radicais livres, antialérgicos, antiinflamatórios, antimicrobianos, antivirais, anticarcinogênicos, e também atividade como filtro ultravioleta. ${ }^{37,38}$

Devido à baixa solubilidade dos ácidos fenólicos em meio aprótico, sua aplicação em produtos oleosos é muito limitada. A esterificação de sua função ácido carboxílico com álcool graxo aumenta sua hidrofobicidade e resulta em uma molécula anfifílica multifuncional. Tal reação é conhecida como lipofilização, e pode ser obtida quimica ou enzimaticamente. A lipofilização química enfrenta problemas relacionados à labilidade térmica e ao $\mathrm{pH}$ do meio de reação desses compostos. Além disso, a lipofilização química não é seletiva, necessitando diversos passos intermediários e processos de purificação, devido à produção de uma grande quantidade de subprodutos indesejáveis. ${ }^{39}$

A lipofilização enzimática de ácidos fenólicos apresenta vantagens como condições brandas de reação, maior especificidade seletiva, com menor formação de subprodutos, maior variedade de substratos sintéticos puros, e menor número de passos intermediários e de subprodutos de reação. A lipofilização enzimática é atualmente

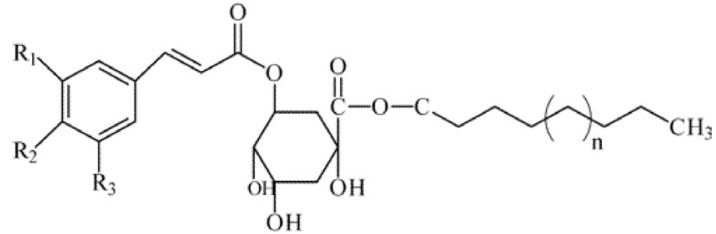

Figura 1. Estrutura química dos derivativos do ácido cinâmico
A<smiles>[R]c1cc(C(=O)O)c([R])c([R3])c1[R]</smiles>

B<smiles>[R]c1cc(C(=O)OCCCCCCCCC)c([R])c([R])c1[2H]</smiles>

Figura 2. Estrutura química dos derivativos do ácido benzóico (A) e dos ésteres alcoólicos derivativos do ácido benzóico $(B)$

estudada utilizando lipases, feruloilesterases, tanases e cutinases. ${ }^{8}$ Stamatis et al. $^{40}$ realizaram a esterificação de ácido ferúlico com 1-octanol utilizando diferentes enzimas, dentre as quais a cutinase de Fusarium solani pisi. Estas enzimas também se mostraram capazes de catalisar a esterificação de ácido cinâmico, $p$-cumárico e $p$-hidroxifenil propiônico a velocidades relativamente altas.

\section{Degradação de inseticidas e pesticidas}

Os inseticidas organofosforados são largamente utilizados para o controle de pragas na agricultura e no tratamento de parasitas na pecuária. ${ }^{41,42}$ Tais compostos permanecem no ambiente, principalmente em substâncias lipídicas, sendo rapidamente absorvidos por praticamente todas as vias, incluindo o trato gastrointestinal, pele, membranas mucosas e pulmões. ${ }^{43}$

A partir de testes em laboratório e da experiência de campo com o uso do produto, os organofosforados têm se mostrado nocivos ao sistema nervoso central de invertebrados, sistema imune de vertebrados e glândulas adrenais e fígado de peixes, além de produzirem mutações detectáveis em células sanguíneas e linfáticas humanas. ${ }^{44}$

Kim et $a l .{ }^{45}$ estudaram a biodegradação e detoxificação do organofosforado malation utilizando cutinase de Fusarium oxysporum e esterase de levedura. A porcentagem de degradação do inseticida pela cutinase foi cerca de $60 \%$ da quantidade inicial durante os primeiros $30 \mathrm{~min}$ e cerca de $50 \%$ foi decomposto nos primeiros $15 \mathrm{~min}$. Com o uso da esterase de levedura, cerca de $65 \%$ do malation permaneceu não decomposto mesmo após 2 dias de tratamento. A composição química final após 2 dias foi significativamente dependente da enzima utilizada. A cutinase fúngica resultou em malation diácido (MDA) como principal produto de degradação. Contudo, na degradação do malation pela esterase de levedura, um isômero do malation monoácido (MMA) foi produzido em abundância. Efeitos tóxicos do malation e de seus produtos de degradação foram investigados utilizando bactérias recombinantes bioluminecentes. Os produtos de degradação obtidos utilizando esterase (incluindo MMA) causaram severo dano de membrana e inibição da síntese protéica nas bactérias. Com o uso da cutinase fúngica, o malation foi degradado principalmente para o produto não tóxico MDA.

Walz e Schwack ${ }^{46}$ descreveram o desenvolvimento de um ensaio enzimático espectrofotométrico baseado na inibição da cutinase de Fusarium solani pisi por pesticidas organofosforados. A finalidade de tal ensaio foi a detecção de resíduos de pesticidas em alimentos. A cutinase demonstrou ser a enzima mais apropriada para a finalidade de análise de pesticidas. Foi demonstrado que o ensaio proposto tem 
capacidade de análise de resíduos em níveis extremamente baixos. Em um estudo subseqüente, ${ }^{47}$ os autores submeteram diversos organofosforados e carbamatos a tal teste. Os organofosforados oxons são detectados pelo teste em níveis extremamente baixos, enquanto os thions são inibidores fracos da cutinase, porém podem ser transformados em seus análogos oxon, através da introdução de uma etapa oxidativa prévia ao teste. Os pesticidas carbamatos também foram testados, revelando-se inibidores eficientes da cutinase embora menos potentes que os organofosforados.

\section{Tratamento e lavagem de tecidos}

$\mathrm{Na}$ industria têxtil as fibras sintéticas representam quase $50 \%$ de todo o mercado mundial. ${ }^{48} \mathrm{~A}$ produção de fibras de poliéster é maior que a de fibras de algodão. Devido à importância das fibras sintéticas, existe um grande interesse em pesquisa relacionada à melhora dos processos de produção, bem como à melhora das características do produto.

As fibras sintéticas apresentam características como hidrofobicidade, que as tornam pouco confortáveis ao contato com a pele humana, e baixa reatividade, que dificulta o tratamento com agentes finalizantes, tais como corantes. Tratamentos empregando agentes alcalinos fortes melhoram a hidrofilicidade e reatividade química de tais fibras, mas tais processos são de difícil controle, freqüentemente resultando em graus variáveis de perda de resistência do tecido. ${ }^{8,49,50}$ Além disso, a grande quantidade de hidróxido de sódio e as altas temperaturas necessárias tornam o processo pouco atraente do ponto de vista ambiental. A modificação das propriedades das fibras em busca de menor hidrofobicidade deve limitar-se à superfície, sem alterar as propriedades do interior. Atualmente existe grande interesse no uso de enzimas como lipases e cutinases, as quais têm mostrado melhorar a hidrofilicidade de poliésteres através da hidrólise de ligações éster. ${ }^{50,51}$ Devido ao tamanho dessas enzimas, sua atuação ocorre apenas na superfície das fibras. As reações ocorrem sob condições mais brandas e não há necessidade de grande maquinaria para a realização do processo, o qual apresenta baixo nível de resíduos. ${ }^{52,53}$

Cutinases e carboxilesterases têm demonstrado potencial de hidrolisar ligações éster de forma similar às lipases. ${ }^{54}$

Sendo a cutinase um eficiente catalisador, tanto em solução quanto em interface água-lipídeo, é potencialmente adequada para a remoção de manchas de gordura em tecidos. A implementação da enzima como ingrediente em detergentes na indústria de roupas está limitada pelo desdobramento da enzima na presença de surfactantes aniônicos. Segundo Creveld et al., ${ }^{55}$ o aumento da estabilidade da cutinase de Fusarium solani pisi poderia ser obtido por mutações desenhadas para evitar a formação transitória de grupamentos hidrofóbicos durante a movimentação da proteína.

Vertommen et al..$^{50}$ realizaram a modificação enzimática de uma superfície de polietileno tereftalato utilizando cutinase de Fusarium solani pisi e lipase A de Candida antarctica em sistema aquoso. A cutinase demonstrou atividade hidrolítica significativa sobre o polímero, não tendo sido registrada atividade significativa em presença da lipase.

Silva et al. ${ }^{48}$ utilizaram a cutinase de Fusarium solani pisi para modificar a superfície de fibras sintéticas de poliéster, poliamida e acrílicos. A cutinase foi escolhida para atuar na modificação das fibras devido a sua hidrofobicidade e ação em biopoliésteres presentes na cutina das plantas. A atividade em poliamida foi determinada através da produção de hexametilenodiamina. A atividade em poliéster foi determinada através da produção de ácido tereftálico, e em acrílico, através da detecção de ácido acético. A maior parte dos resíduos de aminoácidos próximos ao sítio ativo da enzima são hidrofóbicos, possivelmente melhorando as interações entre a enzima e as fibras têxteis. A cutinase demonstrou poder hidrolisar ligações amidas tendo uma maior atividade em poliamida que em poliéster.

Degani et al..$^{56}$ empregaram cutinase para melhorar a umectabilidade de fibras de algodão. O efeito da cutinase foi estudado de forma isolada e em co-reação com pectinaliase. A combinação de cutinase e pectinaliase apresentou efeito sinérgico. O uso de detergentes também aumentou a eficiência de reação.

\section{Química de polímeros}

$\mathrm{Na}$ indústria de polímeros, novos paradigmas estão surgindo em virtude da escassez de fontes de matérias-primas tradicionais, bem como do manejo de resíduos. Algumas enzimas em meio não aquoso têm se mostrado ativas em uma ampla gama de reações de síntese de poliésteres e policarbonatos. A maioria de tais enzimas são da família das lipases, sendo a lipase B de Candida antarctica a mais utilizada. A cutinase de Humicola insolens (Novozymes ${ }^{\circledR}$ ) demonstrou atividade promissora em lactonas de anel aberto e reações de polimerização por condensação. ${ }^{57}$ A maioria das investigações em biotransformação catalisadas por cutinase tem se concentrado na degradação de poliésteres e na esterificação ou transesterificação de pequenas moléculas. ${ }^{54}$

Mais de meio século atrás, os polímeros sintéticos passaram a substituir os materiais naturais em quase todas as áreas, e atualmente os plásticos se tornaram indispensáveis à vida moderna. A estabilidade e durabilidade dos plásticos têm sido melhoradas continuamente, fazendo desse grupo de materiais sinônimo de resistência a influências ambientais e microbianas. A grande produção de plásticos durante as últimas décadas resultou em problemas de manejo dos resíduos desses materiais. Devido ao seu curto tempo de existência na natureza, a evolução não pôde desenhar novas estruturas enzimáticas capazes de degradar polímeros sintéticos. Há cerca de 20 anos atrás os cientistas começaram a pesquisar a possibilidade de produzir plásticos vulneráveis ao ataque microbiano, tornando-os biodegradáveis em um meio ambiente microbiano ativo, mas ainda mantendo suas propriedades favoráveis ${ }^{58}$ Desde o início ficou evidente que polímeros com heteroátomos na cadeia principal, tais como, poliésteres, poliéteres, poliamidas e poliuretanos, podem ser degradados por microorganismos e o desenvolvimento de plásticos biodegradáveis foi dominado predominantemente por materiais derivados de poliésteres. ${ }^{59,60}$

O estudo de enzimas hidrolíticas selecionadas pela evolução para degradar polímeros naturais altamente estáveis, como celulose, quitina e cutina, pode ser especialmente útil para a compreensão dos mecanismos pelos quais polímeros naturais e sintéticos são degradados por enzimas microbianas (Figura 3). Esse conhecimento é necessário para o desenvolvimento de novos plásticos biodegradáveis. ${ }^{61}$

Plásticos baseados em poliidroxidecanoatos são biodegradáveis, porém seu custo de produção é elevado. ${ }^{61}$ Policaprolona é um poliéster sintético que é degradado por uma variedade de microorganismos, mas suas propriedades físicas limitam suas aplicações. Murphy et $a l .{ }^{62}$ demonstraram que a cutinase de Fusarium solani pisi tem a capacidade de degradar a policaprolona.

Ftalatos são plastificantes utilizados na produção de cloreto de polivinil e, freqüientemente, pinturas laquês e cosméticos ${ }^{63,64}$ Diexilftalato (DHP) é um dos ésteres de ftalato comumente utilizados, empregado em brinquedos, luvas de vinil, sapatos e em embalagens de alimentos. Os ftalatos, incluindo o DHP, têm sido considerados poluentes ambientais, e mesmo sendo controlados em vários países, os seres humanos estão expostos a eles diretamente através de ingestão, inalação e exposição cutânea. ${ }^{65}$

Kim et al. ${ }^{45}$ estudaram a eficácia da cutinase de Fusarium oxysporum e esterase de Candida cylindracea na degradação do DHP. A cutinase atua de forma muito mais rápida e precoce que a esterase, com alta atividade hidrolítica. A degradação do DHP pela cutinase 


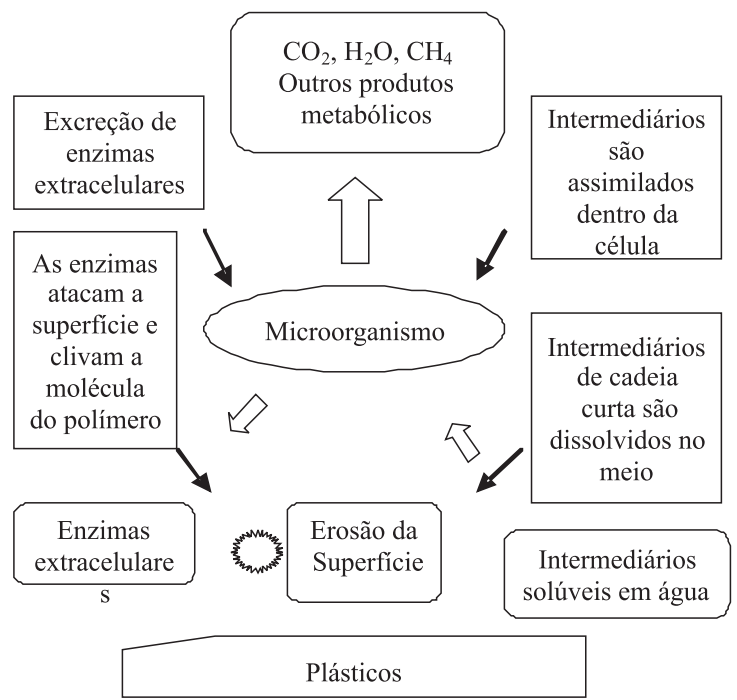

Figura 3. Mecanismo geral de degradação de plásticos catalisada por enzimas hidrolíticas

foi cerca de $70 \%$ do DHP inicial em $4 \mathrm{~h}$, enquanto que mais de $85 \%$ do DHP permaneceu inalterado com o uso da esterase, após 3 dias. A toxicidade dos produtos de reação foi avaliada utilizando bactérias recombinantes bioluminescentes. Os produtos de hidrólise da cutinase não causaram nenhum dano celular observável, o mesmo não ocorrendo com a esterase.

\section{Reações de esterificação enantiosseletiva}

A importância do uso de enzimas em biocatálise tem se mostrado cada vez mais evidente. A grande versatilidade de reações catalisadas, as condições brandas de reação, a natureza regio, quimio e enantiosseletiva são algumas de suas vantagens. ${ }^{66}$ Devido a sua enantiosseletividade, algumas cutinases têm sido empregadas em vários processos deste tipo por meio de hidrólise ou síntese, Figura 4.

Mannesse et al. ${ }^{67}$ sintetizaram análogos de triglicerídeos de cadeias de tamanhos variados com enantiômeros $\mathrm{R}$ e $\mathrm{S}$ para estudar a influência do comprimento da cadeia na posição 1-, 2-, e 3- na atividade de cutinase e estereopreferência. A enzima hidrolisou preferencialmente o enantiômero R, mas essa preferência foi fortemente dependente do comprimento da cadeia acil, com atividade R:S de 30:1. A enantiosseletividade foi encontrada em três diferentes sistemas.

Borreguero et al. ${ }^{9}$ testaram a regio e enantiosseletividade de cutinase recombinante de Fusarium solani pisi em três fenil-alcanodióis racêmicos e um pró-quiral por transesterificação irreversível com vinil acetato em meio orgânico. Para testar a habilidade da enzima na estereodiscriminação
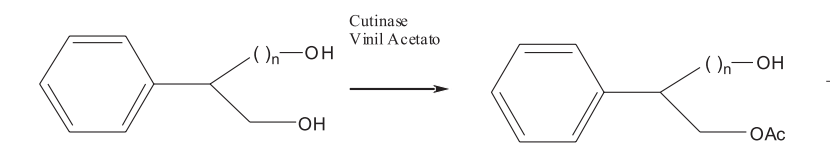

$$
\begin{array}{lr}
\mathrm{n}=0 & ( \pm)-1 \\
\mathrm{n}=1 & 2 \\
\mathrm{n}=2 & ( \pm)-3 \\
\mathrm{n}=4 & ( \pm)-4
\end{array}
$$
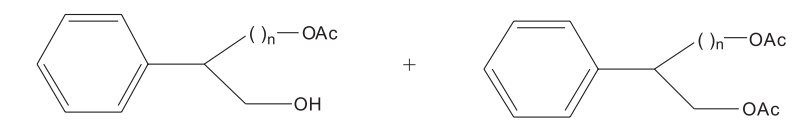

$\mathrm{n}=0( \pm)-7$

$$
\mathrm{n}=0( \pm)-8
$$

destes substratos, demonstrou-se que o aumento da estereosseletividade da acilação do grupo primário hidroxil foi obtido com a pré-incubação da enzima em presença do substrato diol 1, entretanto, não houve correlação com o tempo de incubação. Os autores também demonstraram que o vinil acetato exerceu um efeito estabilizador sobre a enzima, similar ao demonstrado pelo hexanol em micelas reversas.

\section{Indústria alimentícia}

No processo industrial de obtenção de xarope de açúcar a partir de amido de trigo, a principal impureza é a hemicelulose, proveniente da parede celular, a qual não é degradada no processo, cujo acúmulo pode comprometer o processo de filtração. A hemicelulose é um heteropolissacarídeo contendo xilana, que é esterificado com arabinofuranosídeo e ácido ferúlico. Esta xilana modificada não pode ser completamente hidrolisada apenas pela xilanase, porém quando esta enzima é combinada com arabinofuranosidase e esterase de ácido ferúlico torna-se possível remover de maneira eficiente tais resíduos. Porém, como estas enzimas são termolábeis, existe a necessidade de obtenção de enzimas termoestáveis com perfil de atividade semelhante. Neste contexto, Andersen et al. ${ }^{68}$ pesquisaram lipases e cutinases fúngicas quanto à atividade de esterase de ácido ferúlico. As cutinases de Aspergillus oryzae, Fusarium solani pisi e Humicula insolence apresentaram atividade superior às lípases testadas, para os valores de $\mathrm{pH}$ de 5,0; 7,0 e 9,0; com os melhores resultados encontrados para a cutinase de $H$. insolence. Tais enzimas possuem perfil de estabilidade bastante adequado para o processo industrial, sendo candidatas a modificações genéticas objetivando aumentar a atividade de esterase de ácido ferúlico.

\section{CONCLUSÃO}

As cutinases são enzimas que apresentam propriedades de lipases e esterases e, adicionalmente, possuem a propriedade única de atividade independente da presença de interface. Esta característica possibilita o seu uso como biocatalisador em diversos sistemas, envolvendo reações de hidrólise, esterificação e transesterificação. Estas enzimas têm sido foco de intensa e crescente pesquisa, com expressivo número de patentes registradas, embora seu uso industrial em larga escala ainda não esteja implementado.

O potencial da biotecnologia para melhorar as propriedades de matérias-primas naturais e submetê-las a transformações profundas, bem como para o tratamento de resíduos industriais e degradação de produtos tóxicos ou pouco biodegradáveis, já foi comprovado. A demanda industrial por tecnologia enzimática vem aumentando gradativamente. As cutinases podem tornar-se importantes protagonistas nesse contexto.

\section{AGRADECIMENTOS}

À FAPESP e ao CNPq pelo apoio financeiro.

\section{REFERÊNCIAS}

1. Breccia, J. D.; Krook, M.; Ohlin, M.; Hatti-Kaul, R.; Enzyme Microb. Technol. 2003, 33, 244.

2. Kerry, N. L.; Abbey, M.; Atherosclerosis 1997, 135, 93.

3. Pio, T. A.; Macedo, G. A.; Enzyme Microb. Technol. 2007, 41, 613.

4. Villeneuve, P.; Muderwha, J. M.; Graille, J.; Hass, M. J.; J. Mol. Catal. B: Enzym. 2000, 9, 113.

5. http://www.brenda.uni-koeln.de, acessada em Setembro 2007.

6. Ferreira, B. S.; Calado, C. R. C.; Keulen F.; Fonseca, L. P.; Cabral, J. M. S.; Fonseca, M. M. R.; J. Biotechnol. 2004, 109, 159.

7. Egmond, M. R.; De Vlieg, J.; Biochimie 2000, 82, 1015.

8. Soares, C. M.; Teixeira, V. H.; Baptista, A. M.; Biophys. J. 2003, 84, 1628. 
9. Borreguero, I.; Carvalho, C. M. L.; Cabral, J. M. S.; Sinisterra, J. V.; Alcántara, A. R.; J. Mol. Catal. B: Enzym. 2001, 11, 613.

10. Melo, E. P.; Baptista, R. P.; Cabral, J. M. S.; J. Mol. Catal. B: Enzym. 2003, 22, 299

11. Petersen, S. B.; Johnson, P. H.; Fojan, P.; Petersen, E. I.; Petersen, M T. N.; Hansen, S.; Ishak, R. J.; Hough, E.; J. Biotechnol. 1998, 66, 11.

12. Kolattukudy P. E. Em Lipases; Borgstrom, B.; Brockman, T., eds.; Elsevier: Amsterdam, 1984, p. 471.

13. Carvalho, C. M. L.; Serralheiro, M. L. M.; Cabral, J. M. S.; AiresBarros, M. R.; Enzyme Microb. Technol. 1997, 22, 117.

14. Carvalho, C. M. L.; Aires-Barros, M. R.; Cabral, J. M. S.; Biotechnol. Bioeng. 1999, 60, 17.

15. Carvalho, C. M. L.; Aires-Barros, M. R.; Cabral, J. M. S.; J. Biotechnol 2000, 81,1 .

16. Melo, E. P.; Costa, S. M. B.; Cabral, J. M. S.; Fojan, P.; Petersen, S. B.; Chem. Phys. Lipids 2003, 124, 37.

17. Ternström, T.; Svendsen, A.; Akke, M.; Adlercreutz, P.; Biochim. Biophys. Acta 2005, 1748, 74.

18. Sebastião, M. J.; Cabral, J. M. S.; Aires-Barros, M. R.; Biotechnol. Bioeng. 1993, 42, 326.

19. Gonçalves, A. M.; Schacht, E.; Matthjis, G.; Aires-Barros, M. R.; Cabral, J. M. S.; Gil, M. H.; Enzyme Microb. Technol. 1999, 24, 60.

20. Macedo, G. A.; Pio, T. F.; Braz. J. Microbiol. 2005, 36, 388.

21. Filipsen, J. A. C.; Appel, A. C. M.; Van Der Hidjen, H. T. W. M.; Verrips, C. T.; Enzyme Microb. Technol. 1998, 23, 274.

22. Klibanov, A. M.; Nature 2001, 409, 241.

23. Clauss, J.; Óleos e Grãos 1996, 5, 31

24. Gonçalves, L. A. G.; Óleos e Grãos 1996, 5,27.

25. Ahmed, J. I.; Food Sci. Technol. Res. 1995, 9,228.

26. Lima, J. R.; Nassu, R. T.; Quim. Nova 1996, 19, 127.

27. Casey, J.; Macrae, A. R.; Inform. 1992, 3, 203.

28. Gunstone, F. D.; Fett-Lipid 1999, 101, 124.

29. Hammond, E. G.; Glatz, B. A. Em Food Biotechnology; Kling, R. D.; Cheetham, P. S. J., eds.; Elsevier Publishers Limited: Amsterdam, 1988.

30. Regado, M. A.; Cristóvão, B. M.; Moutinho, C. G.; Balcão, V. M.; AiresBarros, R.; Ferreira, J. P. M.; Malcata, F. X.; Int. J. Food Sci. Technol. 2007, 42, 961 .

31. Gillies, B.; Yamazaki, H.; Armstrong, D. W.; Biotechnol. Lett. 1987, 10, 709.

32. Armstrong, D. W.; Gillies, B.; Yamazaki, H. Em Flavour Chemistry, Trends and Development; Charalambous, G., ed.; Elsevier Science Publishers: New York, 1989.

33. Longo, M. A.; Sanromán, M. A.; Food Technol. Biotechnol. 2006, 44 335.

34. Vandamme, E. J.; Soetaert, W.; J. Chem. Technol. Biotechnol. 2002, 77, 1323.

35. Larsson, K. M.; Adlercreutz, P.; Mattiasson, B.; Biotechnol. Bioeng. 1990, 36, 135

36. Barros, D. P. C.; Fonseca, L. P.; Cabral, J. M. S.; J. Biotechnol. 2007, 7 , 188.

37. Silva, F. A. M.; Borges, F.; Guimarães, C.; Lima, J. L. F. C.; Matos, C.; Reis, S.; J. Agric. Food Chem. 2000, 48, 2122.

38. Espinoza, M. C. F.; Villeneuve, P.; J. Agric. Food Chem. 2005, 53 2779.

39. Hills, G.; Eur. J. Lipid Sci. Technol. 2003, 105, 601.

40. Stamatis, H.; Sereti, V.; Kolisis, F. M.; J. Am. Oil Chem. Soc. 1999, 12 , 1505 .

41. Chambers, W. H. Em Organophosphates, Chemistry, Fate, and Effects; Chambers, J. E.; Levi, P. E., eds.; Academic Press: San Diego, 1992.

42. Barlas, M. E.; Environ. Contam. Toxicol. 1996, 57, 705.

43. Indeerjeet, K.; Mathur, R. P.; Tandon, S. N.; Prem, D.; Biomed. Chromatogr. 1997, 11, 352.
44. Galloway, T.; Handy, R.; Ecotoxicology 2003, 12, 345

45. Kim, Y. H.; Ahn, J. Y.; Moom, S. H.; Lee, J.; Chemosphere 2006, 60, 1349 .

46. Walz, I.; Schwack, W.; Eur. Food Res. Technol. 2007, 225, 593.

47. Walz, I.; Schwack, W.; Eur. Food Res. Technol. 2008, 226, 1135

48. Silva, C. M.; Carneiro, F.; O`Neill, A.; Fonseca, L. P.; Cabral, J. M. S.; Guebitz, G.; Cavaco-Paulo, A.; J. Polym. Sci. 2005, 43, 2448.

49. Carvalho, C. M. L.; Aires-Barros, M. R.; Cabral, J. M. S.; Electron. J. Biotechnol. 1998, 1, 28.

50. Vertommen, M. A. M. E.; Nierstrasz, V. A.; Van Der Veer, M.; Warmoeskerken, M. M. C. G.; J. Biotechnol. 2005, 120, 376.

51. Fischer-Colbrie, G.; Heumann, S.; Liebminger, S.; Almansa, E.; CavacoPaulo, A.; Gubitz, G. M.; Biocatal. Biotransform. 2004, 22, 341.

52. Alisch, M.; Feuerhack, A.; Blosfeld, A.; Andreaus, J.; Zimmermann, W.; Biocatal. Biotransform. 2004, 22, 347.

53. Matamá, T.; Silva, C.; O`Neill, A.; Casal, M.; Soares, C.; Gubitz, G. M.; Cavaco-Paulo, A.; $3^{\text {rd }}$ International Conference on Textile Biotechnology, 2004, abstract 5.

54. Yoon, M.; Kellis, J.; Poulouse, A. J.; AATCC Rev. 2002, 2, 33.

55. Creveld, L. D.; Meijberg, W.; Berendsen, H. J. C.; Pepermans, H. A. M.; Biophys. Chem. 2001, 92, 67.

56. Degani, O.; Gepstein, S.; Dosoretz, C. G.; Appl. Biochem. Biotechnol. 2002, 102, 277

57. Hunsen, M.; Azim, A.; Mang, H.; Wallner, S. R.; Ronkvist, A.; Xie, W.; Gross, R.; Macromolecules 2007, 40, 148

58. Mueller, R. J.; Process Biochem. 2006, 41, 2124.

59. Doi, Y.; Microbial polyesters, VCH Publishers: New York, 1990

60. Bastioli, C. Em Degradable polymers, principles and applications; Scott, G.; Gilead, D., eds.; Chapman \& Hall: London, 1995.

61. Mayer, J. M.; Kaplin, D. L.; Trends Polym. Sci. 1994, 2, 227.

62. Murphy, C. A.; Cameron, J. A.; Huang, S. J.; Vinopal, R. T.; Appl. Environ. Microbiol. 1996, 62, 456.

63. Sung, H. H.; Kao, W. Y.; Su, Y. J.; Aquat. Toxicol. 2003, 66, 25.

64. Chang, B. V.; Yang, C. M.; Cheng, C. H.; Yuan, S. Y.; Chemosphere 2004, 55, 533.

65. Kavlock, R.; Boekelheide, K.; Chapin, R.; Cunningham, M.; Faustman, E.; Foster, P.; Golub, M.; Henderson, R.; Reprod. Toxicol. 2002, 16, 709.

66. Carvalho, P. O.; Calafatti, S. A.; Marassi, M.; Silva, D. M.; Contesini, F. J.; Bizaco, R.; Macedo, G. A.; Quim. Nova 2005, $28,614$.

67. Mannesse, M. L. M.; Cox, R. C.; Koops, B. C.; Verheij, H. M.; Haas, G. H.; Egmond, M.; Van Der Hijden, H. T. W.; Vlieg, J.; Biochemistry $1995,34,6400$.

68. Andersen, A.; Svendsen, A.; Vind, J.; Lassen, S. F.; Hjort, C.; Borch, K.; Patkar, S. A.; Colloids Surf. B: Biointerf. 2002, 26, 47.

69. http://v3.espacenet.com/textdoc?DB=EPODOC\&IDX=WO8809367\& $\mathrm{F}=0$, acessada em Junho 2008

70. http://v3.espacenet.com/textdoc?DB=EPODOC\&IDX=JP3088897\& $\mathrm{F}=0$, acessada em Junho 2008

71. http://v3.espacenet.com/textdoc?DB=EPODOC\&IDX=NZ337239\&F= 0, acessada em Junho 2008.

72. http://v3.espacenet.com/textdoc?DB=EPODOC\&IDX=EP1694903\& $\mathrm{F}=0$, acessada em Junho 2008.

73. http://v3.espacenet.com/textdoc?DB=EPODOC\&IDX=JP2005058228 $\& \mathrm{~F}=0$, acessada em Junho 2008

74. http://www.wikipatents.com/ca/2480912.html, acessada em Junho 2008

75. http://www.wikipatents.com/ca/1262860.html, acessada em Junho 2008.

76. http://www.wikipatents.com/ca/2060510.html, acessada em Junho 2008.

77. http://www.wikipatents.com/ca/2465250.html, acessada em Junho 2008. 